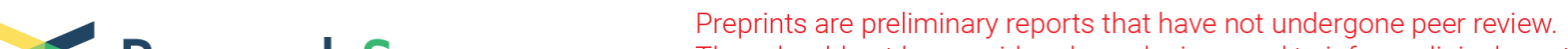 Research Square
or referenced by the media as validated information.
}

\section{Iranian HPV-positive Women's Needs and Preferences in Relation to Receiving Health Services: A Qualitative Study}

\section{Kowsar Qaderi}

Tehran University of Medical Sciences

Mehrnaz Geranmayeh

Tehran University of Medical Sciences

Farnaz Farnam

Tehran University of Medical Sciences

Shahrzad Sheikh Hasani

Tehran University of Medical Sciences

Seyedeh Tahereh Mirmolaei ( $\nabla$ mirmolaei@tums.ac.ir )

Tehran University of Medical Sciences

\section{Research Article}

Keywords: Papillomavirus infections, Health care provider, Expectations, HPV, Women, Cervical Cancer Screening, Needs, Qualitative, Education

Posted Date: January 15th, 2021

DOl: https://doi.org/10.21203/rs.3.rs-132454/v1

License: (c) (i) This work is licensed under a Creative Commons Attribution 4.0 International License. Read Full License

Version of Record: A version of this preprint was published at BMC Health Services Research on March 31st, 2021. See the published version at https://doi.org/10.1186/s12913-021-06283-w. 


\section{Abstract}

Background: HPV testing is performed in primary care, and in case of abnormal results, the patient is referred to specialized care for follow-up and treatment. Participating in HPV test and receiving an HPV diagnosis can create adverse psychosocial responses. In developing countries that HPV testing recently has been integrated in cervical cancer screening program, to enhance the quality of health services provided to HPV-positive women we need to assess their perceptions. This qualitative study aims to explore HPV-positive women's needs and experiences of receiving health services.

Methods: We conducted 40 semi-structured interviews with HPV-positive women. Recorded interviews transcribed and analyzed using conventional content analysis approach.

Results: Women sought information on HPV types, transmission, prevalence, and clearance. They also required information about other STIs, potential benefits of HPV vaccine, and the risk of HPV-related cancers. Women with abnormal cytology asked about HPV cofactors for cervical cancer. Participants sought ways to improve immunity and sexual health. HPV-positive women's expectations of health care providers (HCPs) include professional principles, communication and counseling skills and HPVknowledge. Women prefer that HCPs treat them with non-judgmental attitude and do not ask for HIV/hepatitis tests immediately after HPV-diagnosis. "Precancerous" and "high-risk" words and watching colposcopy monitor during procedure had made women anxious. Weak referral system and limited interactions among gynecologists and other HCPs highlighted by participants.

Conclusion: The results of this study, based on the experiences and perceptions of HPV women receiving health care, contain messages to healthcare providers at the primary and specialized levels of care to facilitate patient-provider communication around HPV. These practical tips will improve the quality of care for HPV-positive women.

\section{Introduction}

Human Papillomavirus is a common sexually transmitted infection, with potentially serious health consequences like cervical cancer (CC)1, 2. CC is eminently preventable through the availability of HPV vaccination and the possibilities of high-risk HPV screening tests3. Health organizations place a higher priority on HPV testing in developing countries where HPV vaccination coverage is poor3.

In Iran, the national HPV vaccination program has not started but Gardasil can be purchased around $\$ 100$ in some pharmacies. The national CC screening program recommends co-testing (Pap smear and HPV testing) for women aged 30 to 59 every 5 years 4 . Although co-test has been available for two years in all primary healthcare centers throughout the country, public/private insurance plans do not cover cotesting. There are limited government-funded centers in provincial capitals that charge less for screening.

With more women being screened for or diagnosed with HPV, patient education and counseling efforts are increasingly important and more attention should be given to provider-patient communications5. 
Research indicates that participating in HPV test and receiving an HPV diagnosis can create adverse psychosocial responses6-8. In order to avoid anxiety and psychological distress, mass patient education must accompany HPV testing9. Counseling HPV patients presents particular challenges for both physician and patient10.

Promoting patient-centered care practices and good patient-physician communication can lead to positive health outcomes11, 12. In primary healthcare, trust refers to the patients' optimistic believes about care providers and leads to greater patient adherence to care, and better disclosure of sensitive information 13. Emotional and informational support and private counseling space increase patient satisfaction. Patient satisfaction is the comparison of expected care with the patient's perception of care14, 15. Limited studies have investigated HPV communication needs and gaps between HCPs and vaccine-eligible adolescent or HPV-related cancer patients9, 16-20. It would be valuable to provide a deep understanding of HPV-positive women's challenges, views and experiences of communicating HCPs in receiving healthcare21. Moreover, HPV discussion may be more challenging in societies where HPV is not prevalent and it is attached with intense stigma. Therefore, we designed a qualitative interview study to fill this gap by exploring health needs and preferences of HPV-positive women in relation to receiving health services from their perspectives.

Qualitative content analysis research

\section{Methods}

This qualitative content analysis research was conducted from September 2018 to December 2019 at Valiasr outpatient referral gynecology-oncology clinic (located in Imam Khomeini hospital complex serving a large population of women across the country). Five oncologist-gynecologists and two midwives run the clinic. The time given to each patient is limited and the waiting period for this clinic can be as long as 4-6 months for patients needing follow-up visits; therefore, treatment attrition is relatively high.

The clinic coordinator (a midwife) sent all HPV-positive women (either only hrHPV or both high-risk and low-risk strains) to the interviewer (KQ-female- no contact with participants) in a quiet, comfortable room to provide information on the study's goals and methods and invite qualified women to participate in the study. Women were eligible for interview if they were over 18 years of age with a heterosexual partnership; had no serious illness (including CC) and were willing to share experience. A purposeful maximum variation sampling was used to recruit information-rich HPV-positive candidates $(\mathrm{N}=40)$ with a diverse age, marital status, education, and socio-economic status (Table 1). Midwives and gynecologists take cervical examinations in Iran. We also interviewed ten providers (Table 2) at two care levels to explore their communication strategies and recommendations to promote communication with HPV-positive women. 
Table 1

HPV genotypes, cytology results and demographic characteristics of participants

\begin{tabular}{|ll|}
\hline Characteristics & ( $\mathbf{n = 4 0 )}$ \\
\hline HPV Genotypes & \\
\hline High Risk & $21(52.5 \%)$ \\
\hline Mixed (Low \& High Risk) & $19(47.5 \%)$ \\
\hline Pap Test Results & \\
\hline Normal & $13(32.5 \%)$ \\
\hline ASCUS† & $12(30 \%)$ \\
\hline LSIL & $11(27.5 \%)$ \\
\hline HSIL§ & $4(10 \%)$ \\
\hline Age & \\
\hline$<30$ years & $6(15 \%)$ \\
\hline $30-39$ years & $26(65 \%)$ \\
\hline $40-49$ years & $7(17.5 \%)$ \\
\hline$\geq 50$ years & $1(2.5 \%)$ \\
\hline Marital status & $17(27.5 \%)$ \\
\hline Married & $13(32.5 \%)$ \\
\hline Unmarried & $23(57.5 \%)$ \\
\hline Education level & \\
\hline lower Intermediary & $15(37.5 \%)$ \\
\hline University- Bachelor & $25(62.5 \%)$ \\
\hline Master or PhD & \\
\hline Occupation & \\
\hline Housewife & \\
\hline Employed & \\
\hline †Atypical Squamous Cells of Undetermined Significance.
\end{tabular}


Table 2

Demographic characteristics of interviewed providers

\begin{tabular}{|c|c|c|c|c|c|c|c|}
\hline $\begin{array}{l}\text { ID } \\
\text { Number }\end{array}$ & $\begin{array}{l}\text { Healthcare } \\
\text { Provider }\end{array}$ & Age & Sex & Workplace & $\begin{array}{l}\text { Marital } \\
\text { Status }\end{array}$ & $\begin{array}{l}\text { Work } \\
\text { experience } \\
\text { (Years) }\end{array}$ & $\begin{array}{l}\text { Number of } \\
\text { children }\end{array}$ \\
\hline 1 & $\begin{array}{l}\text { Oncologist- } \\
\text { gynecologist }\end{array}$ & 43 & Female & $\begin{array}{l}\text { Valiasr } \\
\text { Clinic }\end{array}$ & Married & 8 & 2 \\
\hline 2 & $\begin{array}{l}\text { Oncologist- } \\
\text { gynecologist }\end{array}$ & 45 & Female & $\begin{array}{l}\text { Private } \\
\text { office }\end{array}$ & Married & 12 & 1 \\
\hline 3 & Gynecologist & 42 & Female & $\begin{array}{l}\text { Valiasr } \\
\text { Clinic }\end{array}$ & Married & 12 & 2 \\
\hline 4 & Gynecologist & 46 & Female & $\begin{array}{l}\text { Private } \\
\text { Clinic }\end{array}$ & Married & 18 & 1 \\
\hline 5 & Gynecologist & 38 & Female & $\begin{array}{l}\text { Valiasr } \\
\text { Clinic }\end{array}$ & Married & 11 & 1 \\
\hline 6 & $\begin{array}{l}\text { Midwife } \\
\text { (Bachelor) }\end{array}$ & 35 & Female & $\begin{array}{l}\text { Private } \\
\text { Clinic }\end{array}$ & Single & 10 & 0 \\
\hline 7 & $\begin{array}{l}\text { Midwife } \\
\text { (Master) }\end{array}$ & 43 & Female & $\begin{array}{l}\text { Valiasr } \\
\text { Clinic }\end{array}$ & Married & 14 & 1 \\
\hline 8 & $\begin{array}{l}\text { Midwife } \\
\text { (Bachelor) }\end{array}$ & 31 & Female & $\begin{array}{l}\text { Valiasr } \\
\text { Clinic }\end{array}$ & Single & 7 & 0 \\
\hline 9 & $\begin{array}{l}\text { Midwife } \\
\text { (Master) }\end{array}$ & 47 & Female & $\begin{array}{l}\text { Private } \\
\text { office }\end{array}$ & Married & 15 & 2 \\
\hline 10 & $\begin{array}{l}\text { Virologist (Lab } \\
\text { Director) }\end{array}$ & 48 & Male & $\begin{array}{l}\text { Private } \\
\text { Laboratory }\end{array}$ & Married & 16 & 2 \\
\hline
\end{tabular}

A total of 40 female HPV-positive Persians with diverse ethnic, cultural and religious backgrounds interviewed (semi-structured face-to-face) during waiting hours. Interview guide started with demographic context and screening history (Appendix 1). Two women declined to participate, choosing not to discuss HPV. Three pilot interviews (included in study) were conducted to improve questions. Memos helped create next interview questions. In-depth interviews with consent of participants were recorded (35-90 minutes), transcribed verbatim, and collected until data saturation was reached over 15 months.

The accuracy of this qualitative study was assured based on the four parameters of Guba and Lincoln: credibility, reliability, confirmability, and transferability 22,23 . The credibility criterion was achieved by prolonged engagement and member checking. Peer debriefing and external checking ensured performance confirmability and reliability. Two observers reviewed all transcripts, codes, and categories. Lastly, this process concluded with several discussions among the research team on areas of disagreement before achieving final consensus. We tried to consider maximum variation during sampling 
to enhance transferability. In qualitative study, generalizability was labeled as a full description of setting, participants, and categories in rich detail through the outside reader's lens. To achieve reliability, the study procedure was described comprehensive. Direct quotes from participants have presented.

Qualitative content analysis method, described by Burnard et al.24, was performed using MAXQDA-10 software simultaneously with data collection. Initially, interview transcripts, memos, and field notes were integrated, and two coders (KQ and STM) read transcripts repeatedly to formulate a general understanding of entire data. Open coding was conducted. The extracted codes were combined with similarities and variations. In higher abstraction levels, sub-categories with related content were interpreted into the main categories.

This study is coming from a Ph.D. thesis on Reproductive Health, a mixed method study titled: 'Concerns and health needs of HPV-positive women: development and evaluation of an intervention.' that was reviewed and accepted by the Ethics Committee of Tehran University of Medical Sciences (date: 29 Oct 2018; registration number: IR.TUMS.FNM.REC.1397.139). Valiasr hospital managers willingly facilitated the study. Written informed consent obtained from all participants.

\section{Results}

Participant characteristics shown in Table 1 demonstrate the heterogeneity of sample. Women averaged 34.07 years ( $21-52$ years). All had visited healthcare providers regarding their HPV infection in the 12 months preceding the interview. Half received a diagnosis from a gynecologist, fifteen percent from a general practitioner and remain from a primary healthcare provider. All saw a provider other than the one who initially diagnosed them.

Women were asked about their experiences with providers through a series of questions (Appendix 1 ). The analysis of the data led to the extraction of three main categories, including: communication and counseling skills, commitment to professional principles, and HPV-knowledge of providers (Table 3).

Details in parentheses following quotes represent the participant's identification number (W.=HPV-positive Woman, Pr.=Provider). 
Table 3

Needs and Perceptions of Iranian HPV-positive women about receiving health care

\section{Categories \\ 1. Communication and Counseling Skills}

sub-categories

a. HPV Discussion

\section{Example of codes}

Skills in breaking bad news

Providing adequate HPV-information with understandable, colloquial language

Taking time to answer the patient's questions

Delivering HPV-information gradually

Avoid exaggerating or underestimating HPV risks

Communicating intentionally inexact about infection source

Counseling about anti-wart treatments

Listen intently to the patient and not to dominate the conversation

b. Emotional

Support and

Acceptance
Paying attention to the patients' feelings and concerns

Encouraging words to strengthen the patient's spirit

The need for compassionate doctors in the medical centers

Doctor's positive attitude towards the woman with an STI

c. Providing
Recommendations

Explaining the risk and providing advice and solutions to reduce the risk

Discussing sexual practice, diet, alcohol and tobacco prohibitions or modification

Vaccine recommendations

d. Clinical

Considerations

Not requesting for HIV and hepatitis tests at the first visit
2.Commitment to Professional Principles

Not sharing the colposcopy monitor with patient unless she wants

Explaining colposcopy before performing it

Not asking/ reporting low-risk HPV strains

a. Gaining

Patients' Trust
Being honest with patient

Adopt non-judgmental attitude toward patient's sexual behavior

Building mutual trust

Discussing the current gaps in HPV-knowledge

Avoid try and error in patients' management 


\begin{tabular}{|c|c|c|}
\hline Categories & sub-categories & Example of codes \\
\hline & \multirow{4}{*}{$\begin{array}{l}\text { c. Confidentiality } \\
\text { and Privacy }\end{array}$} & Visiting patients one by one \\
\hline & & Clinic's staff awareness of the patient's secrecy \\
\hline & & patient privacy in the gynecology clinics \\
\hline & & Consider cultural sensitivity \\
\hline & \multirow{4}{*}{$\begin{array}{l}\text { b. Avoid Financial } \\
\text { Misconduct }\end{array}$} & Avoiding humiliating behaviors towards poor patients \\
\hline & & $\begin{array}{l}\text { Introducing patients to governmental-funded services } \\
\text { instead of private centers }\end{array}$ \\
\hline & & Adopt scientific approaches \\
\hline & & Avoid prescribing self-made medications \\
\hline \multirow{14}{*}{$\begin{array}{l}\text { 3.HPV- } \\
\text { Knowledge of } \\
\text { Providers }\end{array}$} & \multirow{4}{*}{$\begin{array}{l}\text { a. Adherence to } \\
\text { Screening } \\
\text { Guidelines }\end{array}$} & Adopt scientific management and avoid overuse tests \\
\hline & & Screening eligible woman \\
\hline & & Adherence to test intervals \\
\hline & & $\begin{array}{l}\text { Follow-up according to the national cervical cancer } \\
\text { guideline }\end{array}$ \\
\hline & \multirow{5}{*}{$\begin{array}{l}\text { b. Avoid } \\
\text { Misconceptions }\end{array}$} & Discussing the current gaps in HPV-knowledge \\
\hline & & Citing conflicting views \\
\hline & & $\begin{array}{l}\text { Avoid exaggerating about HPV transmission by overusing } \\
\text { protective equipment }\end{array}$ \\
\hline & & $\begin{array}{l}\text { Avoid Instilling fallacy that HPV has a treatment (self-made } \\
\text { suppositories, fungi, and probiotic products) }\end{array}$ \\
\hline & & HCPs' participating in retaining programs \\
\hline & \multirow{5}{*}{$\begin{array}{l}\text { c. Taking } \\
\text { Multidisciplinary } \\
\text { Approach }\end{array}$} & HPV women' need for multidisciplinary team \\
\hline & & Wandering from the duality of therapists' opinions \\
\hline & & Patients frequent referrals to be on the safe side \\
\hline & & $\begin{array}{l}\text { Women's wandering to find required specialist } \\
\text { (Gynecologist-Infectious disease specialist-Oncologist- } \\
\text { Urologist-Dermatologist-ENT specialist-Dentist) }\end{array}$ \\
\hline & & $\begin{array}{l}\text { Counseling women to refer to a genital warts or oral lesions } \\
\text { specialist }\end{array}$ \\
\hline
\end{tabular}

\section{Communication and Counseling Skills}


Women diagnosed with HPV implied communicating preferences and needs in four sub-categories: HPV discussion, emotional support and acceptance, providing recommendations, and clinical consideration.

\section{HPV Discussion}

Women preferred face-to-face delivery of their results (HPV/cytology) to receive complex information about their problem's name, HPV types, symptoms, transmission, prevalence, consequences and treatments. Women sought information on other STIs, potential benefits of HPV vaccine, and the risk of HPV-related cancers. Women with abnormal cytology asked about HPV cofactors for cervical cancer.

They mentioned some points that should be stressed when presenting HPV-information to patients: using plain language, avoiding over-simplifying the disease and sticking to the reality of HPV, gradually transmitting information at multiple appointments, comparing the prevalence of HPV infections and occurrence of cervical cancer (to diminish patients fear of cancer), and expressing that "no one can determine when and from whom a woman get HPV."

Participants showed frustration with providers who break diagnosis news in a way that instilled fear and anxiety.

"When I was told 'You have a problem but it's not cancer', it frightened me to death. I was bursting crying ... I didn't understand what she [doctor] was talking about."(W.16)

The terminology commonly employed by physicians, were mostly unfamiliar to women. Few women indicated that when a doctor considers HPV insignificant, they feel ignored.

"I was so scared. My doctor said: 'cancer patients don't mourn like you. HPV is not that important'. I think insomuch she sees cancer it's gotten trivial for her."(W.26)

To prevent misunderstanding and ensure patient awareness, participants recommended that HCPs provide HPV information over several appointments. Often, patients wished they could ask doctor their questions between visits.

All providers offered examples of women's needs and questions regarding HPV. They implied points that were considered useful. A provider stated:

"Pointing out that HPV is common and most women are unaware of their infection changes women's attitudes toward diagnosing HPV from a threat to an opportunity to prevent cancer."(Pr.8)

To prove that most women with HPV will not develop CC, some providers compare the prevalence of HPV with the incidence of cervical cancer. They believed this comparison reduces patient anxiety.

Some patients expressed dissatisfaction with the time spent by physicians addressing their concerns. They implied time constraint as key barriers to high-quality care. "A few doctors take the time to talk to patient." (W.23) 
Women's questions on HPV were often inadequately answered, particularly in specialized governmental referral clinics. "No gynecologist has the patience to answer questions."(W.12)

Few women reported even primary HCPs having referred them to the specialized clinic without explaining their health problems.

\section{Emotional Support}

Women stated they see their doctor as a source of emotional support. Respondents were more satisfied with compassionate providers who can reassure frightened patients.

"Every illness needs a good doctor. The patient's thoughts are focused on doctor's words. My doctor treated me well. She gave me spirit."(W.2)

According to participants' point of view, the cold, annoying, and repulsive behaviors of the doctor hinders successful follow-up and treatment. They found the doctor's excessive self-protection (e.g. wearing three pairs of gloves) repulsive, but HCPs attributed it to the insufficient knowledge of clinician.

\section{Providing Recommendations}

HCPs had challenges discussing HPV treatment for patients. They acknowledged that telling patients that "HPV has no cure" makes them nervous. On the other hand, HPV infections will clear up or become undetectable on their own and this is promising. A provider stated:

"After saying that 'HPV's most common prognosis is clearance,' some women ask: 'Why hasn't my infection been cleared?' They ask about a test to check the immune system and what can be done to reduce the risk of cancer to negligible levels."(Pr.5)

Women discussed feeling powerless if they can't do anything to maintain their health. Some providers pointed to providing simple, practical and inexpensive tips to strengthen immunity of patients. Women needed advice on sexual health too. A gynecologist-oncologist mentioned: "Due to cultural sensitivities, neither patients nor doctors are inclined to speak about sexual issues."(Pr.1)

Women with apparent genital warts needed additional information on surgical or medical anti-wart therapies.

\section{Clinical Considerations}

Regarding clinical appointments, women needed to be treated gently and respectfully.

"I no longer go to sample due to the intense pain I experienced."(W.22)

Few women expressed anxiety due to hearing the term "precancerous and high-risk" and watching the colposcopy monitor during the procedure.

"I can't get that frightening colposcopy picture off my mind!"(W.9) 
They wanted verbal or written information before the colposcopy procedure. They also preferred HIV and hepatitis tests not be asked at the very first visit.

\section{Commitment to Professional Principles}

Some HPV-positive women were disappointed with healthcare providers' performance. Their statements showed that few HCPs are not fully committed to professional principles.

\section{Gaining Patients' Trust}

Women stated very few doctors had recommended or prescribed unproven medications for HPV cure. Patients were not sure if it was a research project.

Most women pointed to the physicians' success in earning patient confidence as a factor related to care continuity.

"I'm not worried at all because I never get cervical cancer. I'm tested regularly as my doctor said. And if I'm CIN-3[Cervical Intraepithelial Neoplasia], my doctors will fix it." (W.29)

Health professionals mentioned that discussing both what is and is not known about HPV prevents women from confusing and wandering.

"I explain intentionally vague about HPV-transmission to convince my patient that she could have contracted it in almost any way."(Pr.2)

HCPs emphasized that uncertainties such as HPV-vaccination of HPV-infected people should be addressed in HPV-discussion.

\section{Confidentiality and Privacy}

Women were less satisfied with physicians who unintentionally highlight stigma by judging patients' sexual behavior. They did not trust such HCPs and were reluctant to share private information with them. Participants noted that all staff dealing with sexually transmitted patients should be trained in patient secrecy.

"I think OB/GYN visits require the most privacy. I went to a famous GYN clinic. There were other patients in the room besides me. I was embarrassed. Imagine sitting next to a complete stranger who might hear you and talk about sensitive topics that are very difficult to discuss."(W.10)

\section{Avoid Financial Misconduct}

Participants indicated lack of insurance coverage for diagnostic and therapeutic services. Patient pessimistic believes about financial misconducts of HCPs revealed in some interviews. "I paid 10,000,000 
IRR for colposcopy in a private office. If my doctor had referred me here [Valiasr], I could've had a colposcopy for 400,000 IRR! She deliberately did not refer me here!"(W.14)

Few women were upset of HCPs who treat them based on their economic status.

"My doctor recommended colposcopy and when she found out that I had no money for it, she stopped explaining it and did not answer my questions"(W.17)

\section{HPV-Knowledge of Providers}

As an important obstacle to high quality HPV management, participants indicated inadequate knowledge and training in HCPs. Providers pointed to a lack of continuous and integrated training program for physicians and midwives.

\section{Adherence to Screening Guidelines}

Successful management of CC screening is hindered by guideline discordant. A 34-years-old HPV screening eligible woman reported:

"After my husband's genital warts, I went to a gynecologist. I was scared. The doctor said: 'It doesn't matter. Since you don't have a lesion, you don't need HPV testing."(W.31)

A few participants, on the other hand, reported another form of guideline discordant in which some gynecologists appeared to overuse screening tests to provide greater reassurance, whether the HPV-DNA test or the Pap test. To better monitoring of high-risk cases such as $\mathrm{CIN}-2$, most providers have proposed a systematic national registry system.

\section{Avoid misconceptions}

Women exposed misinformation conveyed by a few HCPs who may lack current HPV information. A woman reported that a provider had recommended her cesarean section because of vaginal warts.

Using extra-protective equipment such as wearing three pairs of surgical gloves nonverbally indicated to a misconception that non-sexual transmission of the virus is serious.

\section{Taking Multidisciplinary Approach}

More than half of the women interviewed had seen at least three doctors in the 12 months before the interview. Satisfaction and HPV-knowledge did appear to rise among this subset of women.

Patients reported attending to a number of different HCPs including general practitioner, gynecologistoncologist, dental professional, infectious disease specialist, dermatologist, dentist, urologist, nurse, lab technician, and midwife. According to participants' point of view, there is not an optimal cross-disciplinary referral system among gynecologists and other HCPs. 
A woman with oral ulcers worried about HPV-related precancerous oral lesion. "I've seen ENT specialist and dentist to get other opinions just to be on the safe side."(W.28)

Participants indicated that physicians' conflicting opinions on HPV vaccination and using condoms in those already infected with HPV were among the reasons to frequent visits.

\section{Discussion}

The perceptions and preferences clearly described in this study may provide deeper insight to HCPs working with HPV-infected people to establish evidence-based strategies to support patient-provider communication around HPV. Findings indicated that providers' communication strategies is as important as content. The way in which information on HPV is conveyed needs careful consideration. How providers communicate women about their HPV results can have an influence on their emotional responses to HPV diagnosis25.

Findings noted that healthcare providers should be cautious in choosing their words; since ASCCP consensus (2020) is hesitant that pre-cancer is the best definition for CIN2 or CIN3 and higher26, 27.

Using new risk tables, to risk estimates, and management of abnormal screening tests, which are freely available online at https://CervixCa.nlm.nih.gov/RiskTables,28 could alter providers' interpretation of positive results.

Women verified that requesting HIV-test in the first appointment after diagnosis requires consultation. Gynecologists should consider that some women prefer not to look at the colposcopy monitor during the procedure.

In this study women expected caregivers to spend enough time to answer their questions. Due to the limited number of gynecologist-oncologists, it is expected that at the primary level of care, more time can be allocated for patient education and counseling than specialized level. In addition, to provide basic HPV-information, waiting room posters or leaflets or an educational website could be beneficial. Therefore more time will leave to face-to-face appointments to answer questions and make a patientcentered two-way HPV communication19, 29.

HPV testing may lead to questions regarding sexual history, which clinicians should be prepared to discuss30. Iranian religious beliefs that physicians may hold about sexuality can be a barrier to optimal sexual health care31. In our setting, midwives are qualified communicators because they are of the same sex and are trained for sexual counseling.

Our findings suggest ways to build trust, such as addressing current gaps in HPV-knowledge. Gaining patient confidence is critical in decisions to receive medical services, compliance, and healthcare satisfaction13. Another study2 addressed the importance of disclosing existing limitations in HPVknowledge with patients. 
A study indicated that HPV patients may perceive certain physician behavior as negative even though the doctor does not plan to30. HPV patients may be more pessimistic in societies with religious-cultural sensitivity and strong stigma. Caregivers should note that these cultures have instilled a STI of embarrassment and guilt. HCPs are critical in informing patients and moderating patients' psychosocial response.

Our results emphasize the need for patient consent to participate in HPV clearance trials. This is not only their right, but also increases their trust. The success of physicians in gaining patient trust leads to continued treatment.

Providers should be aware of the privacy and secrecy issues associated with an STD diagnosis, particularly in culturally sensitive societies. A study noted privacy as a factor of high-quality primary services 14.

Due to the high cost of colposcopy, Iranian health insurance providers were suggested to include CC screening procedures in their service packages 32.

Our study showed that HCPs require continuing education programs for guideline adherence and updated knowledge. Doctors must make deliberate efforts to improve their HPV-related communication skills34, 35 Gynecologists' awareness of the provision of the HPV-DNA test, such as time intervals and test series, was unsatisfactory in another study. It was because of the multiplicity and rapidly evolving guidelines33. Potential overuse of HPV testing among women's health providers was reported in another study34. This may indicate the patient-centered care or knowledge deficiency. Further studies are needed to characterize compliance of providers with national guidelines for HPV testing.

As previous studies have emphasized, doctors, medical students, and dental providers need training to provide appropriate basic HPV-knowledge to patients $16,35,36$. HCPs also should know that HPV may contaminate protective equipment but HPV-DNA transfer to medical personnel is unlikely to occur37.

Since the most women interviewed had visited at least three doctors, Iranian physicians must follow a multidisciplinary approach and, knowing their own limitations, refer patients to proper specialist facilities as a first step towards effective management.

We acknowledge the study's limitations. Our study environment was one busy specialized center for HPVpatients so it is possible that emerged themes would be different from other clinics nationally. Therefore, caution is required when interpreting data. We should comment on the potential influence of a highly educated sample ( $60 \%$ with university education) as another limitation. Naturally, qualitative research is not targeted at representativeness, but it seems likely that less-educated women's viewpoints were not thoroughly explored. Some of the findings are cultural-specific and cannot be generalized to all communities.

Like other qualitative studies, the generalizability and relative weight of emergent categories are not obvious. This paper follows COREQ checklist for reporting qualitative studies38. Participants in this study 
may have been more comfortable talking about HPV. They may also have personal prejudices towards doctors or other care providers, which may affect their experiences and expectations. Findings do not necessarily generalize health care in developing countries.

\section{Conclusions}

The results of this study, based on the experiences and perceptions of HPV women receiving health care, contain messages to healthcare providers at the primary and specialized levels of care to facilitate patient-provider communication around HPV. These practical tips will improve the quality of care for HPVpositive women, which is an integral component of cervical cancer prevention programs.

- HPV-positive women sought information on HPV types, transmission, prevalence, clearance and the risk of HPV-related cancers, and HPV cofactors for cervical cancer.

- Women need advice on vaccinations, follow-up, sexual health, and boosting immunity.

- HPV-positive women's expectations of health care providers (HCPs) include professional principles, communication and counseling skills and HPV-knowledge.

- Exposing current HPV-knowledge limitations and gaps prevent women from excessive clinical referrals.

- Providers should be cautious in using words "high-risk" and "precancerous".

\section{Abbreviations}

HPV: Human Papillomavirus

CC: Cervical cancer

HCPs: Health Care Providers

\section{Declarations}

\section{Details of Ethics Approval}

Written informed consent was obtained from all the participants. This study has been performed in accordance with the Declaration of Helsinki and has been reviewed and approved by the Ethics Committee of Tehran University of Medical Sciences (IR.TUMS.FNM.REC.1397.139).

\section{Consent for publication}

Not applicable 


\section{Availability of data and materials}

The data that support the findings of this study are available from the corresponding author, [STM], upon reasonable request.

\section{Competing Interests}

The authors have no conflict of interest.

\section{Funding}

The research was funded by Tehran University of Medical Sciences for a Ph.D. thesis in Reproductive Health.

\section{Acknowledgments}

We thank the colposcopy clinic staff at the Valiasr Hospital and everyone who helped with recruitment and all the women who participated in the study. This study is coming from a Ph.D. thesis on Reproductive Health, a mixed method study titled: 'Concerns and health needs of HPV-positive women: development and evaluation of an intervention.' Another manuscript from this doctoral dissertation (Reproductive concerns of HPV-positive women) has been submitted in another journal.

\section{Authors' Contributions}

KQ, STM, MG, FF, and SSH designed the study. KQ conducted the interviews. STM and KQ planned and undertook the analysis. KQ wrote the initial and subsequent drafts of the manuscript. STM, MG, FF, and SSH contributed to revising the manuscript. All authors read and approved the final manuscript.

\section{References}

1. Friedman LS, Kahn J, Middleman AB, Rosenthal SL, Zimet GD. Human papillomavirus (HPV) vaccine: a position statement of the Society for Adolescent Medicine. The Journal of adolescent health : official publication of the Society for Adolescent Medicine. 2006;39(4):620.

2. Centre IIHI. Iran: Human Papillomavirus and Related Cancers, Fact Sheet. 2018. ICO/IARC HPV Information Centre, 2018.

3. Campos NG, Tsu V, Jeronimo J, Mvundura M, Kim JJ. Evidence-based policy choices for efficient and equitable cervical cancer screening programs in low-resource settings. Cancer medicine.

2017;6(8):2008-14. 
4. Kousha A MA, Maleki A, Najmi M, Dini M, Arjmandpour M. Package of Essential Non-communicable (PEN) disease interventions for primary health care in Iran "IRAPEN". Tehran: Mojassameh; 2017.56 p.

5. Lin L, Benard VB, Greek A, Roland KB, Hawkins NA, Saraiya M. Communication practices about HPV testing among providers in Federally Qualified Health Centers. Preventive medicine reports. 2015;2:436-9.

6. McCaffery K, Waller J, Forrest S, Cadman L, Szarewski A, Wardle J. Testing positive for human papillomavirus in routine cervical screening: examination of psychosocial impact. BJOG : an international journal of obstetrics and gynaecology. 2004;111(12):1437-43.

7. McCaffery K, Waller J, Nazroo J, Wardle J. Social and psychological impact of HPV testing in cervical screening: a qualitative study. Sexually transmitted infections. 2006;82(2):169-74.

8. Perrin KK, Daley EM, Naoom SF, Packing-Ebuen JL, Rayko HL, McFarlane M, et al. Women's reactions to HPV diagnosis: insights from in-depth interviews. Women \& health. 2006;43(2):93-110.

9. Anhang R, Goodman A, Goldie SJ. HPV communication: review of existing research and recommendations for patient education. CA: a cancer journal for clinicians. 2004;54(5):248-59.

10. Denny-Smith T, Bairan A, Page MC. A survey of female nursing students' knowledge, health beliefs, perceptions of risk, and risk behaviors regarding human papillomavirus and cervical cancer. J Am Acad Nurse Pract. 2006;18(2):62-9.

11. Kahn JA, Emans SJ, Goodman E. Measurement of young women's attitudes about communication with providers regarding Papanicolaou smears. The Journal of adolescent health : official publication of the Society for Adolescent Medicine. 2001;29(5):344-51.

12. Robinson JH, Callister LC, Berry JA, Dearing KA. Patient-centered care and adherence: definitions and applications to improve outcomes. J Am Acad Nurse Pract. 2008;20(12):600-7.

13. Sadeghi-Bazargani H, Tabrizi JS, Zare Z, Saadati M. Psychometric properties of primary health care trust questionnaire. BMC health services research. 2019;19(1):502.

14. Mohammad-Alizadeh CS, Wahlström R, Vahidi R, Nikniaz A, Marions L, Johansson A. Barriers to high-quality primary reproductive health services in an urban area of Iran: views of public health providers. Midwifery. 2009;25(6):721-30.

15. Kasa AS, Gedamu H. Predictors of adult patient satisfaction with nursing care in public hospitals of Amhara region, Northwest Ethiopia. BMC Health Serv Res. 2019;19(1):52.

16. Goff SL, Mazor KM, Gagne SJ, Corey KC, Blake DR. Vaccine counseling: A content analysis of patient-physician discussions regarding human papilloma virus vaccine. Vaccine. 2011;29(43):7343-9.

17. Kornides ML, Fontenot HB, McRee A-L, Panozzo CA, Gilkey MB. Associations between parents' satisfaction with provider communication and HPV vaccination behaviors. Vaccine. 2018;36(19):2637-42.

18. Fang CY, Heckman CJ. Informational and Support Needs of Patients with Head and Neck Cancer: Current Status and Emerging Issues. Cancers of the head \& neck. 2016;1. 
19. Gilkey MB, Moss JL, Coyne-Beasley T, Hall ME, Shah PD, Brewer NT. Physician communication about adolescent vaccination: How is human papillomavirus vaccine different? Preventive medicine. 2015;77:181-5.

20. Gilkey MB, McRee A-L. Provider communication about HPV vaccination: a systematic review. Human vaccines \& immunotherapeutics. 2016;12(6):1454-68.

21. O’Connor M, O’Donovan B, Waller J, Céilleachair AÓ, Gallagher P, Martin C, et al. Communicating about HPV in the context of head and neck cancer: A systematic review of quantitative studies. Patient education and counseling. 2020;103(3):462-72.

22. Polit DF, Beck CT. Nursing research: Generating and assessing evidence for nursing practice: Lippincott Williams \& Wilkins; 2008.

23. Lincoln YS, Guba EG. But is it rigorous? Trustworthiness and authenticity in naturalistic evaluation. New directions for program evaluation. 1986;1986(30):73-84.

24. Burnard P, Gill P, Stewart K, Treasure E, Chadwick B. Analysing and presenting qualitative data. British dental journal. 2008;204(8):429.

25. O'Connor M, Costello L, Murphy J, Prendiville W, Martin CM, O'Leary JJ, et al. 'I don't care whether it's HPV or ABC, I just want to know if I have cancer.' Factors influencing women's emotional responses to undergoing human papillomavirus testing in routine management in cervical screening: a qualitative study. BJOG : an international journal of obstetrics and gynaecology. 2014;121(11):14219.

26. Schiffman M, Wentzensen N, Perkins RB, Guido RS. An Introduction to the 2019 ASCCP Risk-Based Management Consensus Guidelines. Journal of Lower Genital Tract Disease. 2020;24(2):87-9.

27. Landy R, Schiffman M, Sasieni PD, Cheung LC, Katki HA, Rydzak G, et al. Absolute risks of cervical precancer among women who fulfill exiting guidelines based on HPV and cytology cotesting. International journal of cancer. 2020;146(3):617-26.

28. Egemen D, Cheung LC, Chen X, Demarco M, Perkins RB, Kinney W, et al. Risk estimates supporting the 2019 ASCCP risk-based management consensus guidelines. Journal of Lower Genital Tract Disease. 2020;24(2):132-43.

29. Reitano M. Counseling patients with genital warts. The American journal of medicine. 1997;102(5):38-43.

30. Fakhry C, D'Souza G. Discussing the diagnosis of HPV-OSCC: Common questions and answers. Oral oncology. 2013;49(9):863-71.

31. Rashidian M, Minichiello V, Knutsen SF, Ghamsary M. Barriers to sexual health care: a survey of Iranian-American physicians in California, USA. BMC health services research. 2016;16(1):263.

32. Joulaei H, Zarei N. Women's Cancer Care in Iran. Cancer Control. 2019;26(1):1073274819848432.

33. Caglioti C, Pileggi C, Nobile CG, Pavia M. Gynecologists and human papillomavirus DNA testing: exploring knowledge, attitudes, and practice in Italy. Eur J Cancer Prev. 2017;26(3):249-56. 
34. Hallett LD, Gerber MR. Human Papillomavirus Testing by Veterans Administration Women's Health Providers: Are They Adhering to Guidelines? Journal of women's health (2002). 2018;27(2):179-82.

35. Baay MF, Verhoeven V, Peremans L, Avonts D, Vermorken JB. General practitioners' perception of risk factors for cervical cancer development: consequences for patient education. Patient education and counseling. 2006;62(2):277-81.

36. Kline N, Vamos C, Thompson E, Catalanotto F, Petrila J, DeBate R, et al. Are dental providers the next line of HPV-related prevention? Providers' perceived role and needs. Papillomavirus research (Amsterdam, Netherlands). 2018;5:104-8.

37. Ilmarinen T, Auvinen E, Hiltunen-Back E, Ranki A, Aaltonen LM, Pitkäranta A. Transmission of human papillomavirus DNA from patient to surgical masks, gloves and oral mucosa of medical personnel during treatment of laryngeal papillomas and genital warts. European archives of oto-rhinolaryngology : official journal of the European Federation of Oto-Rhino-Laryngological Societies (EUFOS) : affiliated with the German Society for Oto-Rhino-Laryngology - Head and Neck Surgery. 2012;269(11):2367-71.

38. Tong A, Sainsbury P, Craig J. Consolidated criteria for reporting qualitative research (COREQ): a 32item checklist for interviews and focus groups. International journal for quality in health care. 2007;19(6):349-57.

\section{Supplementary Files}

This is a list of supplementary files associated with this preprint. Click to download.

- supplementaryfile.docx 